\title{
Desafios da formação docente em Química: a concepção dos acadêmicos de um Curso de Licenciatura em Ciências da Natureza
}

\author{
Desafíos de la formación docente en Química:la concepción de los \\ académicos de un Curso de Licenciatura en Ciencias de la Naturaleza \\ Challenges of teacher education in Chemistry: the conception of the \\ academics of a Degree in Natural Sciences
}

\author{
Quelen Colman Espíndola Lima ${ }^{1}$ \\ Simone Silva Alves ${ }^{2}$ \\ Vitor Garcia Stoll ${ }^{3}$
}

\begin{abstract}
Resumo
Este trabalho demonstra os dados resultantes de uma pesquisa realizada com futuros docentes do nono semestre do curso de Licenciatura em Ciências da Natureza (LCN) da Universidade Federal do Pampa do município de Dom Pedrito - RS. O objetivo central foi identificar alguns desafios enfrentados durante a formação docente no que tange à componente de Química, e entender quais são as expectativas e concepções desses acadêmicos em relação ao trabalho do educador na contemporaneidade. Para tanto, foi elaborado um questionário estruturado com formato objetivo com dezenove licenciandos do nono semestre do curso de LCN. Os resultados denotaram que, entre outros, a compreensão dos conteúdos específicos foi uma das principais dificuldades ao logo do curso, bem como a contextualização dos conteúdos foi apontada como sendo o principal desafio a ser transposto em sala de aula.
\end{abstract}

Palavras-Chave: Dificuldades e desafios, Formação docente, Licenciatura em Ciências da Natureza.

\section{Resumen}

Este trabajo demuestra los datos resultantes de una investigación realizada con futuros docentes del noveno semestre del curso de "Licenciatura em Ciencias da Natureza" (LCN), de la "Universidade Federal do Pampa" del municipio de Dom Pedrito - RS. El objetivo central fue identificar algunos desafios enfrentados durante la formación docente en lo que se refiere a la componente de Química y entender cuáles son las expectativas y concepciones de eses académicos en relación al trabajo del educador en la contemporaneidad. Para lo tanto, fue elaborado un cuestionario estructurado con formato objetivo con diecinueve licenciandos del noveno semestre del curso de LCN. Los resultados denotaron que, entre otros, la comprensión de los contenidos específicos fue una de las principales dificultades a lo largo del curso, así como la contextualización de los contenidos fue señalada como siendo el principal desafío a ser transpuesto en clase.

Palabras claves: Dificultades y desafíos, Formación docente, "Licenciatura em Ciências da Natureza".

\footnotetext{
${ }^{1}$ Licenciada em Ciências da Natureza; Universidade Federal do Pampa Campus Dom Pedrito - UNIPAMPA; Dom Pedrito, Rio Grande do Sul, Brasil; quelenespíndola13@gmail.com.

${ }^{2}$ Doutora em Educação; Universidade Federal do Pampa Campus Jaguarão - UNIPAMPA; Dom Pedrito, Rio Grande do Sul, Brasil; simonealves@ unipampa.edu.br

${ }^{3}$ Licenciado em Ciências da Natureza; Universidade Federal do Pampa Campus Dom Pedrito - UNIPAMPA; Dom Pedrito, Rio Grande do Sul, Brasil; quelenespíndola13@gmail.com.
} 


\begin{abstract}
This work demonstrates the results of a research carried out with future non-semester lecturers in the Licentiate in Nature Sciences (LCN) program at the Federal University of Pampa in the Municipality of Dom Pedrito - RS. The central objective was to identify some of the challenges faced during teacher training in the discipline of chemistry and knowledge are as expectations and concepts academic dictionaries in relation to the work of the educator in the contemporaneity. For this purpose, a structured questionnaire with an objective format was elaborated with nineteen graduates from the ninth semester of the LCN course. The results are different from the most important difficulties of the course logo, as well as a contextualization of contents to be adapted as the main challenge for transposing in the classroom.
\end{abstract}

Keywords: Difficulties and challenges, Teacher training, Degree in Natural Sciences.

\title{
1. Introdução
}

A formação de professores no cenário atual da educação brasileira, é um contexto para o qual se deve atentar substancialmente. Segundo Imbernón (2011, p.113), os estudos sobre a temática é recente, mas “o interesse por esse tema vem aumentando e reflete-se na atenção que lhe dedicam uma série de publicações educativas [...]", o que se justifica por uma crescente inquietação em conhecer, compreender e refletir sobre o assunto. Há necessidade de diálogos, debates e reflexões acerca da formação de professores, na tentativa de delinear, mesmo que vagarosamente, possíveis soluções que poderão colaborar positivamente para futuras mudanças na área da formação docente.

Para Purin (2011) o trabalho docente é constituído pelo conjunto de práticas que ultrapassa o contexto da sala de aula, dizem respeito à historicidade dos sujeitos, a correlação existente entre gestão/professor/alunos, as condições concretas de trabalho e as políticas públicas que norteiam essas relações. Desse modo, a profissão professor não é mais caracterizada como transmissão do conhecimento acadêmico, nem tampouco como transformação do conhecimento comum em científico. De acordo com Imbernón, tal profissão tem outras funções, como por exemplo: lutar contra a exclusão social; motivar os alunos a despertar a curiosidade científica; inserir-se nas estruturas sociais através do contato direto com os grupos e comunidade. Enfim, participar ativamente do contexto no qual a escola está inserida.

Nessa perspectiva, é oportuno assinalar ainda que, por vezes, os acadêmicos matriculados nos cursos de Licenciatura, independente da área, nos primeiros semestres de formação, encontram muitas dificuldades relativas à compreensão dos conteúdos profissionais específicos (GALIAZZI, 2014). Tais dificuldades, muitas vezes, são decorrentes de lacunas em suas formações durante a Educação Básica. Porém, geralmente, o frágil desempenho acadêmico é condicionando à complexidade dos conteúdos, à metodologia de ensino ou de avaliação dos professores do curso. Acerca deste aspecto, o Relatório da UNESCO (2014) 
menciona que é fundamental um ensino de qualidade na Educação Básica, para que se alcance bons resultados na graduação.

Diante do exposto e visando um panorama reflexivo acerca da formação docente, o objetivo deste trabalho é identificar alguns desafios enfrentados durante a formação dos acadêmicos do nono semestre do curso de Licenciatura em Ciências da Natureza (LCN) da Universidade Federal do Pampa, Unipampa - Campus Dom Pedrito/RS. O enfoque da referida pesquisa foi direcionado ao ensino de Química, área com relevante expressividade de componentes constituindo a matriz curricular do curso. Considerando ainda a possibilidade de que esses futuros docentes futuramente exerçam seu trabalho nas escolas de Ensino Médio do município, que atualmente, ainda trabalham com componentes independentes, ou seja, a Biologia, a Física e a Química, ensinadas separadamente.

Essa pesquisa também é destinada a evidenciar as perspectivas dos formandos no tocante a sua futura prática escolar, enquanto professor na área da Química. Em subsequência apresenta-se a metodologia utilizada, os resultados obtidos e as considerações finais do estudo.

\section{Delineamento metodológico}

Buscando compreender melhor o contexto da formação inicial dos estudantes de licenciatura - futuros professores - foi realizada uma pesquisa fundamentada nas bases teórico-metodológicas de Triviños (2003). A referida pesquisa foi direcionada a identificar alguns aspectos que permeiam o ensino de Química - disciplina pertencente às Ciências de Natureza. O objetivo central foi conhecer as principais dificuldades enfrentadas no decorrer da formação desses sujeitos, as concepções dos mesmos acerca da condição formativa em Química, além das suas expectativas sobre o trabalho do professor dessa área, na atualidade. A partir deste pressuposto, Paviani (2005, p. 207), destaca que "o problema científico surge da descoberta de que o nosso conhecimento não é suficiente para descrever e explicar certas situações".

Para a coleta dos dados pretendidos, foi aplicado um questionário estruturado com formato objetivo/dissertativo, a treze licenciandos do nono semestre do curso de LCN, tendo representatividade de $68,5 \%$ dos prováveis formandos. As questões foram elaboradas com alternativas de múltipla escolha, entretanto, o pesquisado ainda poderia optar por responder de forma dissertativa, no espaço destinado na alternativa "outro". O Quadro 01 exemplifica as questões utilizadas na pesquisa. 
RELACult - Revista Latino-Americana de Estudos em Cultura e Sociedade

Revista Latinoamericana de Estudios en Cultura y Sociedad | Latin American Journal of Studies in Culture and Society V. 04, ed. especial, fev., 2018, artigo n ${ }^{\circ}$ 781 | relacult.claec.org | e-ISSN: 2525-7870

Quadro 1 - Questões utilizadas na pesquisa

\begin{tabular}{|c|c|c|c|}
\hline $\begin{array}{l}\stackrel{2}{0} \\
\stackrel{0}{0} \\
\stackrel{0}{2}\end{array}$ & $\begin{array}{l}\text { 1. Entre os itens elencados abaixo, } \\
\text { qual você considera ter sido o } \\
\text { principal desafio enfrentado na } \\
\text { sua formação docente, em relação } \\
\text { à disciplina de Química? }\end{array}$ & $\begin{array}{l}2 . \text { Com base na sua } \\
\text { trajetória acadêmica, como } \\
\text { você descrever sua } \\
\text { formação em Química para } \\
\text { atuar como docente nesta } \\
\text { área, nos dias atuais? }\end{array}$ & $\begin{array}{l}\text { 3. De acordo com suas experiências } \\
\text { no âmbito escolar, assinale uma das } \\
\text { alternativas que poderá ser, } \\
\text { atualmente, a maior dificuldade a ser } \\
\text { superada pelos professores de } \\
\text { Química. }\end{array}$ \\
\hline 胥 & $\begin{array}{l}\text { ( ) Compreender } \\
\text { satisfatoriamente os conteúdos } \\
\text { ( ) Aprender o vocabulário } \\
\text { científico } \\
\text { ( ) Correlacionar os conteúdos } \\
\text { com o mundo em que vivemos } \\
\text { ( ) Outro: Pode citar - }\end{array}$ & $\begin{array}{l}\text { ( ) Suficiente } \\
\text { ( ) Razoável } \\
\text { ( ) Insuficiente } \\
\text { ( ) Outro: Pode citar - } \\
\text { Por quê? }\end{array}$ & $\begin{array}{l}\text { ( ) Domínio do conteúdo a ser } \\
\text { ensinado } \\
\text { ( ) Indisciplina dos alunos } \\
\text { ( ) Contextualização do conteúdo de } \\
\text { acordo com a realidade dos alunos } \\
\text { ( ) Permanente atualização na área } \\
\text { ( ) Falta de recursos na instituição } \\
\text { de Ensino. } \\
\text { ( ) Outro: Pode citar - }\end{array}$ \\
\hline
\end{tabular}

Fonte: Os autores

Os resultados obtidos foram organizados categoricamente em uma planilha criada no Excel, com a finalidade de facilitar a leitura e análise dos dados, bem como evitar possíveis erros.

\section{Resultados e discussões}

No que tange ao perfil dos pesquisados, dos treze acadêmicos participantes da pesquisa, dez eram do sexo feminino $(77 \%)$ e três do sexo masculino $(23 \%)$, com faixa etária compreendida entre 20 e 54 anos.

Em relação ao primeiro questionamento, a maioria dos acadêmicos (62\%), indicou que compreender satisfatoriamente o conteúdo foi o principal desafio enfrentado na formação docente referente à componente de Química, conforme o ilustrado no Gráfico 1.

Gráfico 1 - Desafios enfrentados na formação docente em relação à disciplina de Química

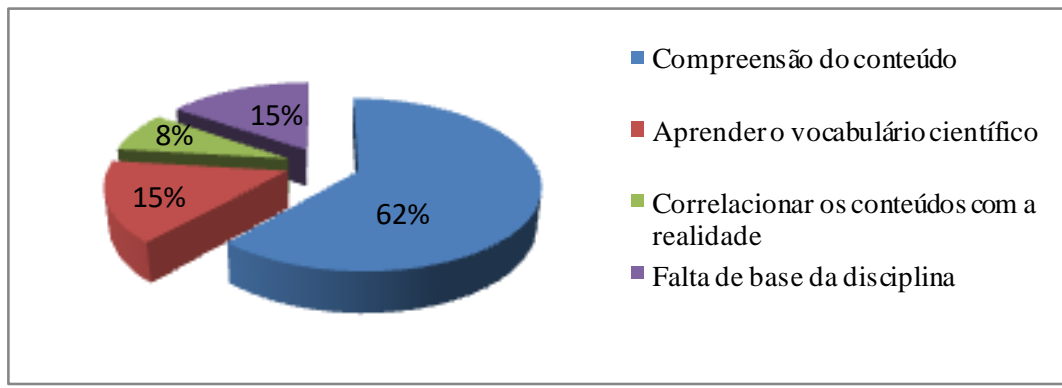

Fonte: Os autores

Identificou-se ainda, que parte dos pesquisados apontaram que a principal dificuldade centrou-se em aprender corretamente vocabulário científico da Química, e outros entendem que a falta de base da componente, decorrente da formação anterior (Ensino Médio, Curso 
Normal ou EJA), foi o desafio mais relevante na sua trajetória de formação docente. Um dos participantes da pesquisa atribuiu sua maior dificuldade ao fato de não conseguir correlacionar os conteúdos estudados à realidade do mundo.

Em relação a esse contexto, a narrativa de Carvalho e Pérez (1995, p.71) nos diz que "alguns dos obstáculos que hoje se dão na formação dos professores, desaparecerão quando as vivências escolares dos futuros professores forem mais positivas [...]". Conforme corrobora Imbernón (2011, p. 17)

A aquisição de conhecimentos por parte do professor está muito ligada à prática profissional e condicionada pela organização da instituição educacional em que está inserida. Por isso é tão importante desenvolver uma formação na instituição educativa, uma formação no interior da escola (IMBERNON, 2011, p. 17).

Desse modo, destaca-se a relevância da prática docente na formação dos licenciados, pois, à medida que se vivencia o contexto escolar, experiencia-se na prática o que é estudado na teoria. No curso de LCN, os licenciandos possuem quatro componentes curriculares destinadas à prática docente: Estágio Supervisionado I (observação e vivência do contexto escolar); Estágio Supervisionado II (observação e vivência da sala de aula); Estágio Supervisionado III (docência no Ensino Fundamental) e Estágio Supervisionado IV (docência no Ensino Médio).

Todas essas componentes estimulam a formação investigativa, onde os graduandos produzem ao longo de seus estágios, notas de campo e diários reflexivos para que, em um primeiro momento, sejam utilizados como instrumento de formação docente e, posteriormente, como objeto de análise para a produção do artigo ou relatório de conclusão do componente curricular (STOLL, ESPÍNDOLA, BIERHALZ, 2016).

Para Pimenta e Socorro (2010), o Estágio Supervisionado tem como finalidade aproximar o graduando da realidade em que atuará, pois, propicia a reflexão das particularidades e das interfaces escolares e sua contextualização na sociedade. Ao final do estágio, os licenciandos terão construído saberes e despertado inquietações, muitas das quais, só serão sanadas com a experiência profissional.

A segunda indagação visou conhecer a concepção dos acadêmicos sobre as suas condições formativas para atuar como docente na área da Química. Nesta situação, nove pessoas apontaram que tiveram uma formação razoável, quatro delas consideram ter sido suficiente para um bom desempenho das futuras aulas, e nenhuma indicou ser insuficiente. 
Além das opções (suficiente, razoável e insuficiente), a questão ainda buscou saber o porquê da escolha da alternativa, pois é relevante que se tenha conhecimento dos aspectos positivos, bem como das fragilidades existentes neste cenário, o ensino de Química. Assim, dentre as respostas dos licenciandos - considerando que a maioria não participou desta parte da questão - entende-se ser oportuno expor as categorias que apareceram com mais frequência, a fim de refletir posteriormente acerca deste contexto. Atentando para o fato do curso de LCN ser novo no município, e que, possivelmente, sejam necessárias algumas adequações para melhor desenvolvimento e estruturação geral do mesmo.

De acordo com os relatos, o pouco tempo para aprender os conteúdos de Química, a constante troca de professores e suas diferentes metodologias para desenvolver a componente, foram os principais motivos destacados para elucidar o porquê consideram como "razoável" sua formação em Química.

Quanto aos que descrevem sua condição formativa como "suficiente", as principais explicações foram de encontro aos seguintes pontos: aquisição de conhecimentos significativos sobre a Química, bem como uma boa base para dar suporte e nortear o posterior ensino da componente.

Ao serem indagados sobre as dificuldades do profissional do ensino de Química no contexto da sala de aula, ficou evidenciado que a necessária tarefa de contextualizar os conhecimentos científicos com a realidade do aluno foi a categoria mais apontada pelos licenciandos (46\%). Seguida da permanente atualização como professor da área, e da indisciplina e/ou desinteresse dos alunos (23\% cada). A alternativa "domínio de conteúdo" foi destacada em apenas $8 \%$ das respostas, (Gráfico 2).

Gráfico 2 - Dificuldades a serem superadas pelo professor de Química na atualidade

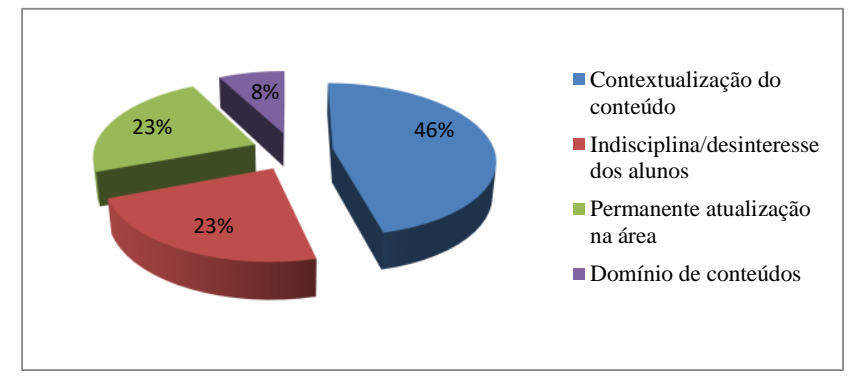

Fonte: Os autores

Ao fazer um panorama geral dos resultados obtidos, constatou-se que, apesar de $62 \%$ dos acadêmicos apontar que, em relação à componente Química, o principal desafio 
enfrentado na formação em LCN tenha sido compreender satisfatoriamente o conteúdo, nenhum deles considera como insuficientes os conhecimentos científicos construídos através da disciplina. De acordo com o Gráfico 2, apenas um dos treze pesquisados denota que o domínio de conteúdo possa ser a principal dificuldade a ser superada pelo futuro professor de Química atualmente.

Assim, infere-se que a dificuldade desses licenciandos em compreender os conteúdos da disciplina de Química, não significa que eles não tenham aprendido tais conteúdos, mas que encontraram dificuldades durante o processo. Fato constatado pela indicação de que a contextualização dos saberes científicos com a realidade dos alunos é o principal desafio a ser vencido pelo professor da área da Química, e não o domínio de conteúdo.

\section{Considerações finais}

Uma das maiores exigências do mercado de trabalho, sem dúvida é a qualificação profissional, no âmbito educacional não é diferente. Portanto faz-se necessário que cada vez mais sejam efetivados os estudos acerca da condição formativa dos futuros docentes. E por meio destes sejam suscitados diálogos e reflexões sobre a formação inicial desses sujeitos, a fim de identificar aspectos passíveis de mudanças em prol de uma formação docente de qualidade.

O contexto evidenciado neste trabalho poderá ser utilizado como subsídio para posteriores propostas de reformulação na estrutura do Curso de LCN, Unipampa - Campus Dom Pedrito. Uma vez que apresenta as concepções da maioria dos licenciandos que constituíram a primeira turma a ser formada pelo respectivo curso, referentes à disciplina de Química, uma das componentes-base da matriz curricular da LCN.

Os acadêmicos dessa primeira turma, brevemente poderão estar atuando nas escolas, sendo imprescindível que esses profissionais recebam uma qualificação que propicie um bom desempenho da práxis em sala de aula e fora dela. Que sejam professores investigadores já que o conhecimento da Química, assim como o de qualquer outra esfera científica, não é algo estagnado e imutável.

Desse modo, considera-se que a dedicação do professor pela busca do conhecimento precisa ir além do "pesquisar para conhecer o que ainda não conheço e comunicar e anunciar a novidade" (FREIRE, 2011, p. 10), ela precisa contribuir para a autoformação profissional e para a formação científica do educando. 


\section{Referências}

CARVALHO, A. M. P. de; PÉREZ, D. G. Formação de professores de Ciências: tendências e inovações. 2.ed. São Paulo: Cortez, 1995.

FREIRE, P. Pedagogia da Autonomia: saberes necessários a prática educativa. São Paulo: Paz e Terra, 2011.

GALIAZZI, M. do C. Educar pela pesquisa: ambiente de formação de professores de Ciências. Ijuí: Ed. Unijuí, 2003.

IMBERNÓN, F. Formação docente e profissional: formar-se para a mudança e a incerteza. 9. ed, São Paulo: Cortes, 2011.

PAVIANI, J. O problema de pesquisa como ponto de partida. Revista Trabalho e Ambiente, Caxias do Sul, v. 3, n. 5, p. 205-222, jul./dez. 2005.

PURIN, P. C. O trabalho docente sob o modo de produção capitalista: Limites e possibilidades de uma práxis emancipadora. In: ZITKOSKI, J. J.; MORIGI, V. Educação Popular e Práticas Emancipatórias: Desafios Contemporâneos. Porto Alegre: Corag, 2011. p. 45 a 57.

Relatório de Monitoramento Global de Educação para Todos UNESCO. Disponível em: http://unesdoc.unesco.org/images/0022/002256/225654por.pdf Acesso em: 24 mar. 2016.

STOLL, V. G.; ESPÍNDOLA, Q. C.; BIERHALZ, C. D. K. Educação de Jovens e Adultos: os desafios dos graduandos de um Curso de Licenciatura em Ciências da Natureza no Ensino de Química. In: Anais Encontro Nacional de Ensino de Química, XVII, 2016, Florianópolis, SC, Brasil. Disponível em: < http://www.eneq2016.ufsc.br/anais/indiceautor.htm\#S > acesso em: 20 Dez 2017.

TRIVIÑOS, A. N. S. Bases Teórico-metodológicas Da Pesquisa Qualitativa Em Ciências Sociais: Ideias gerais para a elaboração de um Projeto de Pesquisa. Porto Alegre: UniTeitter, 2003. 